\title{
Community-Acquired Pneumonia in Adults
}

Martin Kolditz, Santiago Ewig

\section{SUMMARY}

Background: The clinical spectrum of community-acquired pneumonia ranges from infections that can be treated on an outpatient basis, with $1 \%$ mortality, to those that present as medical emergencies, with a mortality above $40 \%$.

Methods: This article is based on pertinent publications and current guidelines retrieved by a selective search of the literature.

Results: The radiological demonstration of an infiltrate is required for the differentiation of pneumonia from acute bronchitis regardless of whether the patient is seen in the outpatient setting or in the emergency room. For risk prediction, it is recommended that the CRB-65 criteria, unstable comorbidities, and oxygenation should be taken into account. Amoxicillin is the drug of choice for mild pneumonia; it should be given in combination with clavulanic acid if there are any comorbid illnesses. The main clinical concerns in the emergency room are the identification of acute organ dysfunction and the management of sepsis. Intravenous beta-lactam antibiotics should be given initially, in combination with a macrolide if acute organ dysfunction is present. The treatment should be continued for 5-7 days. Cardiovascular complications worsen the patient's prognosis and should be meticulously watched for. Structured followup care includes the follow-up of comorbid conditions and the initiation of recommended preventive measures such as antipneumococcal and anti-influenza vaccination, the avoidance of drugs that increase the risk, smoking cessation, and treatment of dysphagia, if present.

Conclusion: Major considerations include appropriate risk stratification and the implementation of a management strategy adapted to the degree of severity of the disease, along with the establishment of structured follow-up care and secondary prevention, especially for patients with comorbidities.

Cite this as:

Kolditz M, Ewig S: Community-acquired pneumonia in adults. Dtsch Arztebl Int 2017; 114: 838-48. DOI: 10.3238/arztebl.2017.0838
Department of Respiratory Diseases, University Hospital Carl Gustav Carus, Dresden: PD Dr. med. Kolditz

Thoraxzentrum Ruhrgebiet, EVK Herne and Augusta-Kranken-Anstalt Bochum, Departments of Respiratory and Infectious Diseases, Bochum: Prof. Dr. med. Ewig
C ommunity-acquired pneumonia (CAP) is, in a global perspective, the infectious disease that most commonly causes death (1). Current figures from health services research in Germany, based on data from the legally mandated health-insurance carriers, reveal an incidence of 9.7 cases per 1000 person-years, corresponding to more than 660000 patients per year. Both the incidence and the mortality of CAP are ageand comorbidity-dependent $(2,3) .46 .5 \%$ of patients with CAP, and more than half of those aged 60 or above, are admitted to hospital for treatment (2). Hospitalized patients with CAP have a high in-hospital mortality of circa $13 \%$ (4). Even after bedridden persons and persons living in nursing homes are excluded from the statistics, $2.4 \%$ of the admitted patients die within 72 hours of admission. These patients account for 33\% of all in-hospital deaths of patients with CAP, or ca. 3700 patients in Germany each year (5).

Acute respiratory insufficiency and acute extrapulmonary organ dysfunction due to sepsis or comorbidities are the most important early prognostic parameters (6-8). Even after discharge from the hospital, there is still a high mortality related to comorbidities, particularly in elderly patients: according to a recent German study, in a group of patients whose median age was over 80 , most of whom had chronic neurological or cardiac disease, the post-discharge mortality within 30 days of hospitalization was $4.7 \%(2,9)$. These figures have led to major conceptual changes in the characterization and treatment of CAP. Aside from early establishment of the goal of treatment in the emergency room, an important initial consideration is to rapidly identify high-risk patients who need to be treated on an emergency basis so that they can have the best possible outcome. Moreover, aspects of post-hospital treatment, prevention, and palliative care for elderly and multimorbid patients need greater attention. These aspects were already incorporated into the revised guideline of 2016 and, in part, implemented in corresponding recommendations (10).

\section{Mortality}

$2.4 \%$ of patients admitted to the hospital with community-acquired pneumonia die within 72 hours of admission. 


\section{Learning goals}

This review should enable the reader to

- know the salient epidemiological features of CAP, including its risk factors and short-term and longterm prognosis;

- initiate appropriate risk stratification leading to valid recommendations for treatment, both in the outpatient setting and in the hospital;

- know the diagnostic and therapeutic steps that should be taken.

\section{Methods}

The PubMed database was selectively searched for publications from April 2015 onward containing the term "community-acquired pneumonia" together with "risk stratification," “diagnosis," "treatment," or "prevention." The current update (2016) of the German guideline on the treatment and prevention of community-acquired pneumonia in adults (10) and its systematic literature search up to March 2015 were also consulted.

\section{Definition}

CAP is defined as pneumonia acquired outside the hospital by an immune-competent individual. It is to be distinguished, on the basis of a wider spectrum of pathogens, from nosocomial pneumonia (which arises more than 48 hours after hospital admission or within 3 months of discharge) and from pneumonia in an immunocompromised host (e.g., in the setting of neutropenia, iatrogenic immunosuppression with drugs, status post organ or stem-cell transplantation, HIV infection, or a congenital immune deficiency) $(10,11)$.

\section{Diagnostic evaluation}

The manifestations of community-acquired pneumonia include respiratory symptoms (cough, sputum, dyspnea, chest pain) and general symptoms of infection (fever, hypothermia, malaise, flu-like symptoms, circulatory symptoms, impaired consciousness), along with the corresponding physical findings (tachypnea, tachycardia, arterial hypotension, focal auscultatory abnormality). As these manifestations are not sensitive or specific enough for definitive diagnosis (e1), a confirmatory chest $\mathrm{x}$-ray is recommended. Infiltrates can also be detected by chest ultrasonography. The following clinical findings elevate the pretest probability that an infiltrate will be present and should prompt a chest $\mathrm{x}$-ray, also in the outpatient setting:

\section{Differentiation from bronchitis}

The demonstration of an infiltrate generally suffices to distinguish CAP from acute bronchitis, which does not need to be treated with antibiotics.

\section{TABLE 1} CRB-65 criteria and additional parameters for risk prediction
before outpatient treatment $(17,18,20)$

\begin{tabular}{l|l|l}
\hline Parameter & CRB-65 criteria & Additional parameters \\
$\begin{array}{l}\text { Impaired } \\
\text { consciousness }\end{array}$ & newly arisen & \\
\hline Respiratory rate & $\geq 30 / \mathrm{min}$ & \\
\hline Blood pressure & $<90 \mathrm{mmHg} / \leq 60 \mathrm{mmHg}$ & \\
\hline Age & $\geq 65$ years & (potentially) decompensated \\
\hline Comorbidities* & & $<90 \%$ \\
\hline Oxygen saturation & & $\begin{array}{l}<5 \% \text { ch } \\
\text { ( }>50 \text { of the day) }\end{array}$ \\
\hline Functional status & & \\
\hline
\end{tabular}

* chronic cardriac, neurological, hepatic, renal, or malignant accompanying disease

- Absence of rhinorrhea

- Dyspnea and/or elevated respiratory frequency

- focal auscultatory abnormality

- Abnormal vital signs (fever, tachycardia $>100 / \mathrm{min}$ )

- Elevated biomarkers (e.g., C-reactive protein [CRP] $>20-30 \mathrm{mg} / \mathrm{L})$.

If more than two of these criteria are met, the pretest probability that an infiltrate will be present in a patient with acute lower airway infection rises from $<5 \%$ to $>18 \%$ (12).

The demonstration of an infiltrate generally suffices to distinguish CAP from acute bronchitis; the latter does not need to be treated with antibiotics because the undesired effects of antibiotic treatment in such cases outweigh their beneficial effect on symptoms (number needed to treat $=22$, number needed to harm $=5$, according to a pertinent meta-analysis) (13). Procalcitonin is another biomarker that can be used to help avoid the unnecessary prescribing of antibiotics to outpatients with lower airway infections (14); if point-ofcare tests are not available, "delayed prescribing" can be used to avoid unnecessary antibiotics.

\section{Evaluation of the goal of treatment}

In Germany, the median age of hospitalized patients with CAP is 76. More than half of all patients have at least one chronic comorbid illness, and $27 \%$ were already chronically bedridden before being admitted with

\section{Predominantly elderly patients}

In Germany, the median age of hospitalized patients with CAP is 76. More than half of all patients have at least one chronic comorbid illness. 


\author{
Management- \\ based risk \\ stratification for \\ community- \\ acquired pneumo- \\ nia in the outpatient \\ setting (from [21])
}

\section{FIGURE 1}

Risk stratification in the outpatient setting

\begin{tabular}{l}
\hline \multicolumn{1}{|c|}{ Definition of the individual goal of treatment } \\
$\qquad$\begin{tabular}{l|l|}
\hline Criteria of severity \\
- Respiratory rate $\geq 30 / \mathrm{min}$ \\
- Blood pressure $<90 / \leq 60 \mathrm{mmHg}$ \\
- New impairment of consciousness \\
- Oxygen saturation $<90 \%$
\end{tabular} \\
\hline $\begin{array}{l}\text { Individual risk factors } \\
\text { - Potentially unstable } \\
\text { comorbiditiy } \\
\text { - Chronic bedridden state }\end{array}$ \\
$\qquad$\begin{tabular}{|l|l|}
\hline Negative criteria: \\
consider outpatient treatment (safe oral medication, no
\end{tabular} \\
social contraindication, no complication)
\end{tabular}

CAP (4). Therefore, a continual re-evaluation and documentation of the goal of treatment for the individual patient, the measures to be taken in pursuit of this goal, and (where applicable) the limitations of treatment are central tasks for the treating physician. The current German guideline deals with these matters in a separate chapter on palliative-care aspects of CAP (10).

\section{The spectrum of pathogens}

By far the most important bacterial pathogen causing CAP in Germany is Streptococcus pneumoniae, which was present in $40 \%$ of patients in the CAPNETZ cohort in whom a pathogen was found (15). Mycoplasma pneumoniae should be considered as well, mainly in patients under age 60 and without comorbid illnesses (16). Further pathogens include Haemophilus influenzae and, in the winter season, influenza viruses. Patients who have chronic comorbid conditions, who live in nursing homes, or who have severe pneumonia may (rarely) be infected with enterobacteria (Escherichia coli, Klebsiella spp.) or Staphylococcus aureus. Legionella spp., too, should always be suspected in patients with severe pneumonia.

\section{Outpatient treatment Risk stratification}

The main goal of risk stratification in the outpatient setting is to accurately identify the patients who are at low risk of dying from pneumonia and are amenable to outpatient treatment. The physician's impression of clinical severity should be objectified with properly validated criteria. The CRB-65 score, which is easy to calculate without requiring any laboratory tests, is recommended in Germany for this purpose (Table 1) (17). Nonetheless, multimorbid patients may have a poor prognosis despite a low score (18), and acute cardiac complications in patients with CAP substantially worsen the prognosis as well (6). Patients must often be hospitalized because of hypoxemia despite a low CRB-65 score (19). The negative predictive value of the CRB- 65 criteria can be markedly improved by the additional consideration of three further parameters - oxygen saturation, potentially decompensated comorbidity, and chronic bedridden state (Table 1) $(18,20)$, as recommended in the current German $\mathrm{S} 3$ guideline, before any decision is taken to treat CAP on an outpatient basis (10). A corresponding risk stratification process for outpatient practice is depicted in Figure 1.

\section{Outpatient treatment of community-acquired pneumonia}

In patients with mild CAP that is amenable to outpatient treatment according to the criteria outlined above, microbiological determination of the pathogen is generally not needed (10). The recommended

\section{Risk stratification}

The CRB-65 score, which is easy to calculate without requiring any laboratory tests, is recommended for risk stratification in the outpatient setting.

\section{Diagnostic evaluation}

In patients with mild CAP that is amenable to outpatient treatment, microbiological determination of the pathogen is generally not needed. 
Empirical initial treatment for mild CAP that can be treated on an outpatient basis (10)

\begin{tabular}{|c|c|c|}
\hline Severity class & Primary treatment (standard dose) & Alternative treatment (standard dose) \\
\hline $\begin{array}{l}\text { Mild pneumonia without comorbidity, } \\
\text { outpatient treatment }\end{array}$ & Amoxicillin (750-1000 mg tid) & $\begin{array}{l}\text { Moxifloxacin ( } 400 \mathrm{mg} \mathrm{qd}) \\
\text { Levofloxacin }(500 \mathrm{mg} \text { qd or bid) } \\
\text { Clarithromycin ( } 500 \mathrm{mg} \text { bid) } \\
\text { Azithromycin }(500 \mathrm{mg} \mathrm{qd} \times 3 \mathrm{~d}) \\
\text { Doxycycline ( } 200 \mathrm{mg} \mathrm{qd})\end{array}$ \\
\hline $\begin{array}{l}\text { Mild pneumonia with comorbidity, } \\
\text { outpatient treatment } \\
\text { - Congestive heart failure } \\
\text { - Neurologic disease with dysphagia } \\
\text { - Severe COPD, bronchiectasis } \\
\text { - Bedridden state, PEG }\end{array}$ & Amoxicillin/clavulanic acid (1 g tid) & $\begin{array}{l}\text { Moxifloxacin ( } 400 \text { mg qd) } \\
\text { Levofloxacin ( } 500 \text { mg qd or bid) }\end{array}$ \\
\hline
\end{tabular}

CAP,community-acquired pneumonia; COPD, chronic obstructive pulmonary disease; PEG, percutaneous endoscopic gastrostomy

antimicrobial treatment of choice for patients without comorbid conditions is monotherapy with high-dose amoxicillin. Patients with mild CAP who have chronic accompanying illnesses should be treated with a combination including a beta-lactamase inhibitor (amoxicillin/clavulanic acid), which widens the spectrum of efficacy to cover $S$. aureus, enterobacteria, and beta-lactamase-producing $H$. influenzae. Patients who are allergic to or cannot tolerate penicillin can be given a fluoroquinolone with efficacy against pneumococci (moxifloxacin, levofloxacin). Randomized trials have shown that the use of these antibiotics on an outpatient basis results in cure rates from $76 \%$ to $89 \%$, without any relevant differences between the individual substance classes (e2). Oral cephalosporins should not be given because of their inadequate oral bioavailability, the elevated risk of selecting extended-spectrum beta-lactamase (ESBL) bacteria, and the risk of Clostridium difficile colitis, along with an elevated risk of treatment failure in the outpatient setting, as shown in the CAPNETZ cohort (odds ratio [OR]: 2.9) (22). The corresponding treatment recommendation is summarized in Table 2. Patients undergoing outpatient treatment should be clinically re-evaluated within 48 to 72 hours, as this is the time frame in which clinical worsening can occur despite ongoing treatment. If the treatment yields no improvement, admission to hospital is necessary in the vast majority of cases. If there is clinical improvement, including defervescence, then the antimicrobial treatment should be continued for 5-7 days at most (10).

\section{The treatment of mild CAP}

The recommended antimicrobial treatment of choice for patients without comorbid conditions is monotherapy with high-dose amoxicillin.

\section{Inpatient treatment}

Risk stratification in the emergency room: CAP as an emergency In the hospital emergency room, risk evaluation is needed so that the treatment of patients at risk can be intensified. Patients who are acutely in need of mechanical ventilation or vasopressor therapy must be transferred to an intensive care unit at once. A recent CAPNETZ study revealed, however, that patients whose condition is stable at first, but deteriorates later on in the course of their hospitalization to the extent that organ-replacement therapy becomes necessary, suffer an additional increase in mortality by as much as $48 \%$ (23). The main predictors of such an

\section{BOX 1}

\section{Minor criteria: if more than 2 of these $\mathbf{9}$ criteria are met, a medical emergency is present (10)}

- Severe acute respiratory insufficiency (partial pressure of oxygen $\leq 55 \mathrm{mmHg}$ or $\leq 7 \mathrm{kPa}$ on room air)

- Respiratory rate $\geq 30 /$ min

- Multilobar infiltrates on chest x-ray

- New impairment of concsiousness

- Systemic hypotension requiring aggressive volume resuscitation

- Acute renal failure (blood urea nitrogen $\geq 20 \mathrm{mg} / \mathrm{dL}$ )

- Leukopenia (leukocyte count $<4000$ cells/ $/ \mathrm{L}$ )

- Thrombocytopenia (platelet count $<100000$ cells $/ \mu \mathrm{L}$ )

- Hypothermia (body temperature $<36^{\circ} \mathrm{C}$ ) 
Risk stratification in the emergency room (from [21]) $\mathrm{FiO}_{2}$, inspired oxygen concentration; $\mathrm{paO}_{2}$, arterial partial oxygen pressure
FIGURE 2

Risk stratification in the emergency room

\begin{tabular}{|c|c|c|c|}
\hline \multicolumn{2}{|c|}{ Definition of the individual goal of treatment } & \multicolumn{2}{|c|}{ Evaluation for acute organ dysfunction, validated by criteria } \\
\hline & \multicolumn{2}{|c|}{$\begin{array}{l}\text { Acute respiratory insufficiency } \\
\text { - Respiratory rate } \geq 30 / \mathrm{min} \\
-\mathrm{paO}_{2} / \mathrm{FiO}_{2}<250 \mathrm{mmHg} \\
\text { - Oxygen saturation }<90 \% \\
\text { - Multilobar infiltrate }\end{array}$} & \\
\hline & \multicolumn{2}{|c|}{$\begin{array}{l}\text { Acute extrapulmonary organ } \\
\text { dysfunction } \\
\text { - Systolic blood pressure }<90 \mathrm{~mm} \mathrm{Hg} \\
\text { or high volume requirement } \\
\text { - Temperature }<36^{\circ} \mathrm{C} \\
\text { - New impairment of consciousness } \\
\text { - Acute renal failure } \\
\text { - Leukocyte count }<4000 / \mu \mathrm{L} \\
\text { - Platelet count }<100000 / \mu \mathrm{L} \\
\text { - Lactate }>2 \mathrm{mmol} / \mathrm{L}\end{array}$} & \\
\hline & \multicolumn{2}{|c|}{ Unstable comorbidity, esp. cardiac } & \\
\hline $\begin{array}{l}\text { O criteria: } \\
\text { Consider outpatient treatment if the } \\
\text { patient's functional status permits }\end{array}$ & $\begin{array}{l}\text { 1-2 criter } \\
\text { Hospitalize } \\
\text { close inter } \\
\text { is achieve }\end{array}$ & $\begin{array}{l}\text { d re-evaluation at } \\
\text { til clinical stability }\end{array}$ & $\begin{array}{l}>2 \text { criteria (emergency): } \\
\text { Intensified monitoring and treat- } \\
\text { ment, consider transfer to intensive } \\
\text { care unit }\end{array}$ \\
\hline
\end{tabular}

occurrence were the following abnormal vital signs on admission:

- Tachycardia and tachypnea

- Low blood pressure

- Hypothermia and

- New impairment of consciousness.

In particular, patients with systemic hypotension, acute respiratory insufficiency, or decompensated cardiac comorbidities are in acute danger of death even if they do not immediately require organ-replacement therapy; they benefit from early intensive treatment of organ dysfunction due to sepsis and comorbid conditions $(6,8,24,25)$. In the current guideline, the use of so-called minor criteria is recommended as a means of objectifying high-risk predictions of this type (Box 1) (10). A recent meta-analysis has shown that all nine of these criteria are predictors for the need for organ-replacement therapy; if more than two criteria are met, the sensitivity and specificity are $79 \%$ and $82 \%$, respectively (positive likelihood ratio: 4.3) (26). Moreover, in an interventional trial, the implementation of a treatment algorithm incorporating these criteria (Box 1) lowered the mortality of high-risk patients of this type from $24 \%$ (in historical controls) to $6 \%$ (25). The evaluation of organ dysfunction due to sepsis must be supplemented by the structured assessment of potentially unstable comorbid conditions; among these, cardiovascular complications such as acute myocardial infarction or left-heart decompensation are of particular prognostic significance (6). An ensuing suggestion for in-hospital, management-based risk stratification is shown in Figure 2.

\section{The management of acute organ dysfunction}

In patients with CAP and acute organ dysfunction, rapid, individualized fluid management and the immediate initiation of intravenous broad-spectrum antibiotic treatment improve the clinical outcome (24, $25)$. Treatment based on so-called sepsis bundles is recommended in the sepsis guidelines (27) (Box 2). Their implementation in the emergency room, including treatment by a physician with experience in intensive-care

\section{High-risk patients}

The identification of high-risk patients and the establishment of treatment goals are the primary initial concerns in the hospital emergency room.

\section{Risk factors}

Systemic hypotension, acute respiratory insufficiency, and a decompensated cardiac comorbidity represent clinical emergencies. 
medicine, can improve outcomes in patients with severe CAP as well and lowers the probability that the patient will later need to be transferred to an intensive care unit $(25, \mathrm{e} 3)$. The serum lactate concentration should also be measured (e4): if it is elevated, rapid, individualized fluid management with re-checking at close intervals is needed, the goal being normalization of the lactate concentration. In patients with acute hypercapnic respiratory insufficiency or accompanying pulmonary edema, non-invasive ventilation should be initiated (10). A recent study showed that nasal highflow oxygen therapy for patients with primary hypoxic respiratory failure tends to lessen the need for intubation and significantly lowers mortality (28).

\section{Microbiological diagnostic evaluation in the hospital}

It is recommended in the German guideline that, as soon as a patient is hospitalized for CAP, blood cultures should be drawn (before the first dose of antibiotic is given, if at all possible), Legionella and pneumococcal antigens should be measured in the urine, and purulent sputum (if present) should be examined microscopically and cultured (10). If the epidemiological setting is suggestive, patients with severe CAP should also be tested for influenza viruses with the polymerase chain reaction (PCR). If mycoplasma pneumonia is suspected, mycoplasma IgM or PCR can be measured; however, the measurement of mycoplasma IgG and IgA is of no diagnostic value, and Chlamydia serology is of no diagnostic value either (e5, e6). If there is a pleural effusion that can be punctured and aspirated, a rapid diagnostic puncture followed by microbiological evaluation and $\mathrm{pH}$ measurement is indicated.

\section{Empirical antibiotic treatment}

In patients with overt organ dysfunction, empirical antimicrobial treatment should be initiated as soon as possible after the diagnosis is made, as this improves the outcome; for all other patients, the initiation of treatment within 8 hours is recommended (10). The initial treatment should be given parenterally for at least 48 hours in a sufficiently high dose and should cover pneumococci, $H$. influenzae, $S$. aureus, and enterobacteria; the agent of choice is an intravenous betalactam antibiotic (Table 3). Even in patients with renal failure, the recommended maximum dose should be given at least for the first 24 hours. For patients with CAP and overt organ dysfunction, the additional administration of a macrolide as part of the initial treat-

\section{Bundle of measures for severe community-acquired pneumonia (10)}

To be performed as rapidly as possible within the first 3 hours:

- Serum lactate measurement

- Blood cultures

- Initiation of appropriate (generally combined) broad-spectrum intravenous antibiotic treatment, within one hour if possible

- In patients with arterial hypotension or elevated serum lactate, rapid intravenous administration of crystalloids

- Evaluation (including blood-gas analysis) and treatment, if needed, of acute respiratory insufficiency

To be performed within the first 6 hours:

- Administration of vasopressors if the response to volume administration is inadequate

- Repetition of lactate measurement if the initial value was elevated

- Re-evaluation of blood gases

ment is recommended, both because this improves outcomes (absolute reduction of mortality from 24\% to $21 \%$ ) (29) and because it covers Legionella in particular. If there is a clinical response and no atypical pathogens are demonstrated, the macrolide drug can be stopped after 3 days of treatment. For hospitalized patients without acute organ dysfunction, an additional macrolide drug is optional, as no clear improvement of the outcome has been demonstrated in prospective, placebo-controlled clinical trials (clinical stability on the $7^{\text {th }}$ day of treatment, $66 \%$ vs. $59 \%, p=0.07 ; 30$-day mortality, $3.4 \%$ vs. $4.8 \%, \mathrm{p}=0.4)(30, \mathrm{e} 7)$.

Pseudomonas aeruginosa causes CAP extremely rarely, $(<1 \%$ of cases in Germany). Risk factors include severe chronic obstructive pulmonary disease (COPD), bronchiectasis, or an indwelling percutaneous endoscopic gastrostomy tube (PEG) (e8). Multiresistant organisms enter into the differential diagnosis only in patients with individual risk factors, such as:

- Prior hospitalization (in which case the recommendations for nosocomial pneumonia apply)

- Prior prolonged broad-spectrum antibiotic treatment

\section{Antimicrobial treatment}

The initial treatment should be given parenterally for at least 48 hours in a sufficiently high dose. The agent of choice is an intravenous beta-lactam antibiotic. 
Empirical initial treatment for in-hospital therapy of community-acquired pneumonia (10)

\begin{tabular}{|c|c|c|}
\hline Severity class & Primary treatment (standard dose) & Alternative treatment (standard dose) \\
\hline $\begin{array}{l}\text { Moderately severe CAP } \\
\text { (no acute organ dysfunction) }\end{array}$ & $\begin{array}{l}\text { Beta-lactam IV } \\
\text { - Amoxicillin/clavulanic acid ( } 2.2 \mathrm{~g} \mathrm{q} 8 \mathrm{~h}) \\
\text { - Ampicillin/sulbactam }(3 \mathrm{~g} \text { q } 8 \mathrm{~h}) \\
\text { - Cefuroxime ( } 1.5 \mathrm{~g} \text { q8h) } \\
\text { - Ceftriaxone }(2 \mathrm{~g} \mathrm{qd}) \\
\text { - Cefotaxime ( } \mathrm{g} \text { q8h) } \\
\text { + Optional* macrolide IV or po for } 3 \text { days } \\
\text { - Clarithromycin ( } 500 \mathrm{mg} \text { q12h) } \\
\text { - Azithromycin ( } 500 \mathrm{mg} \text { qd) }\end{array}$ & $\begin{array}{l}\text { Fluoroquinolone IV or po } \\
\text { Moxifloxacin ( } 400 \mathrm{mg} \text { qd) } \\
\text { Levofloxacin (500 mg qd or q12h) }\end{array}$ \\
\hline $\begin{array}{l}\text { Severe CAP } \\
\text { (acute organ dysfunction) }\end{array}$ & 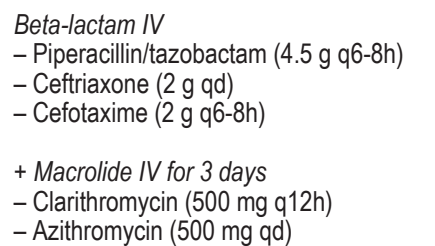 & $\begin{array}{l}\text { Fluoroquinolone IV } \\
\text { Moxifloxacin ( } 400 \mathrm{mg} \mathrm{qd}) \\
\text { Levofloxacin }(500 \mathrm{mg} \mathrm{q1} 2 \mathrm{~h}) \\
\text { (no monotherapy in patients with septic } \\
\text { shock) }\end{array}$ \\
\hline
\end{tabular}

* The additional administration of a macrolide is optional because prospective, placebo-controlled trials have not clearly shown that they improve the outcome

- Prior travel to countries in which multiresistant organisms are prevalent (10).

Additional empirical antiviral treatment with oseltamivir should be considered for hospitalized patients with acute organ dysfunction and elevated risk (comorbid conditions, pregnancy) during the influenza season; oseltamivir should be discontinued as soon as a negative viral test result is obtained by PCR (e9). The recommendations for initial empirical treatment for patients treated in the hospital are shown in Table 3.

\section{Clinical stability and treatment failure}

Because of the dynamic nature of septic organ dysfunction, all patients who meet the criteria for severe CAP or who have abnormal vital signs need continuous monitoring of their disease course until they show clinical improvement. The greatest risk of worsening of organ function is within the first 72 hours after admission to the hospital $(7,8)$. Moreover, laboratory testing for particular types of organ dysfunction is mandatory in patients who have corresponding comorbid conditions. A minimum standard for all hospitalized patients is the re-evaluation of stability criteria once per day (Box 3) (10). If all of these criteria are met, the risk of repeated acute organ dysfunction is low. In addition, another CRP or procalcitonin (PCT) measurement after 3-4 days is recommended; if the value fails to come down after an adequate latency (24-48 hours for PCT, 48-72 hours for CRP), the patient must be clinically re-evaluated for treatment failure.

If clinical stability does not ensue or if there is clinical worsening after 3-5 days of appropriate treatment, the patient must be evaluated for treatment failure. The important clinical distinction must be drawn between a mere delay in the achievement of stability on the one hand and clinically progressive pneumonia on the other. Progressive pneumonia carries a poor prognosis with an up to tenfold increase in mortality. Thus, clinical progression necessitates an immediate diagnostic assessment comprising re-evaluation of severity criteria and organ functions, following up of the inflammatory parameters, and the exclusion of complications such as an abscess or pleural effusion. Care on an intensive care unit for stabilization of organ function and the rapid, appropriate tailoring of the antimicrobial therapy are the main beneficial measures. There should also be a repeated microbiological evaluation, including bronchoscopy if indicated, as well as a meticulous evaluation for extrapulmonary infectious and noninfectious differential diagnoses and complications,

\section{Antiviral treatment}

Additional empirical antiviral treatment with oseltamivir should be considered for hospitalized patients with acute organ dysfunction and elevated risk during the influenza season.

\section{Continuous monitoring of disease course}

All patients who meet the criteria for severe CAP or who have abnormal vital signs need continuous monitoring of their disease course until they show clinical improvement. 
such as pulmonary embolism or hitherto unrecognized immunosuppressed state (including HIV infection). Antibiotic treatment in patients with progressive infection should cover any gaps in the antimicrobial spectrum of the initial treatment and should always be given as intravenous combination therapy in adequate doses (10).

\section{Narrowing or de-escalation of antibiotic treatment}

If there is a clinical response, it should be determined whether the antibiotic treatment can be narrowed or deescalated. For example, in patients being initially treated with a macrolide as part of combination therapy, the macrolide can be discontinued if there is a clinical response and the absence of atypical pathogens is demonstrated. If pneumococci are clearly revealed by blood culture and/or a urinary antigen test, and clinical improvement takes place under empirical treatment, it is recommended that the antibiotic treatment should be narrowed to penicillin (31). Once the criteria for clinical stability have been met, the treatment can be switched to the oral administration of a preparation with good oral bioavailability (e.g., amoxicillin/clavulanic acid) and it should be determined whether the patient is now fit for discharge from the hospital. As long as there are no complications, the treatment should be stopped 2-3 days after clinical stability has been reached; thus, 5-7 days of treatment usually suffice even for severe CAP (32). The implementation of "antibiotic stewardship" may help implementing these steps (33).

\section{Adjuvant treatment: cardiac complications and steroids}

Acute cardiovascular complications arise in up to $14-25 \%$ of all patients hospitalized with $\operatorname{CAP}(6, \mathrm{e} 10)$. In a small, prospective randomized trial, the administration of acetylsalicylic acid (ASA) lowered cardiovascular mortality in 185 hospitalized patients with CAP from $4 \%$ (4 patients) to $0 \%(\mathrm{p}=0.04)(34)$. In an observational study, preexisting medication with ASA was associated with lower in-hospital mortality (e11). Although these preliminary data do not support any general recommendation for the adjuvant administration of ASA to patients with CAP, they do underscore the need to evaluate patients with preexisting cardiac disease repeatedly for potential cardiac complications, as well as the need to re-assess the indication for ASA treatment independently of CAP and to keep giving ASA to patients who were taking it before they developed CAP. Moreover, prophy-

\section{BOX 3}

\section{Criteria for clinical stability (10)}

\author{
The signs of clinical stability are defined as: \\ - Heart rate $\leq 100 / \mathrm{min}$ \\ - Respiratory rate $\leq 24 / \mathrm{min}$ \\ - Systolic blood pressure $\geq 90 \mathrm{~mm} \mathrm{Hg}$ \\ - Body temperature $\leq 37.8^{\circ} \mathrm{C}$ \\ - Ability to take food by mouth \\ - Normal state of consciousness \\ - No hypoxemia $\left(\mathrm{pO}_{2} \geq 60 \mathrm{mmHg}, \mathrm{SaO}_{2} \geq 90 \%\right)$
}

$\mathrm{pO}_{2}$, partial pressure of oxygen; $\mathrm{SaO}_{2}$, oxygen saturation

lactic antithrombotic treatment is recommended for all immobilized patients.

Corticosteroid administration as a potential adjuvant treatment for patients hospitalized with CAP has been studied in multiple clinical trials. The available evidence for a clinically relevant effect is not convincing. Two randomized trials demonstrated no benefit from steroid administration with respect to hard endpoints such as mortality or organ failure $(35, \mathrm{e} 12)$. No general indication for corticosteroid treatment can be derived from these data (10). Systemic corticosteroids are indicated for additionally exacerbated obstructive airway disease or for septic shock that does not respond to catecholamine treatment.

\section{Post-discharge care and secondary prevention}

Patients who have been treated in the hospital for CAP have a statistically significant long-term elevation of mortality compared to matched controls (OR 1.65 over 10 years) (e13). This is accounted for in large measure by deaths from comorbid conditions $(9,36)$. Routine insurance data from Germany reveal high mortality $(4.7 \%)$ in the interval between hospital discharge and 30 days after hospital admission; the patients who died were mainly old (mean age 84) and multimorbid (suffering mostly from cardiac and neurological disease) (2). These findings underscore the need for structured post-discharge care of patients with CAP even after they have reached clinical stability and been discharged from the hospital.

\section{Treatment failure}

If clinical stability does not ensue or if there is clinical worsening after 3-5 days of appropriate treatment, the patient must be evaluated for treatment failure. Progressive pneumonia carries an up to tenfold increase in mortality.

\section{Cardiovascular complications}

Patients with pre-existing cardiac disease need repeated evaluation for potential cardiac complications and reassessment of the indication for ASA treatment. 
There is, however, a lack of scientific evidence and guideline recommendations on this topic. A chest $\mathrm{x}$-ray at some time ( $>2$ weeks) after discharge from the hospital to rule out non-infectious pathological findings is recommended for smokers and for all elderly patients ( $>65$ years) and those with comorbid diseases (10). It seems reasonable as well for patients with chronic accompanying illnesses, such as congestive heart failure, COPD, renal or hepatic insufficiency, or diabetes mellitus, to undergo individually adapted clinical follow-up at close intervals to check for possible organ decompensation, progression, or complications. Moreover, CAP having been identified as an independent long-term risk factor for cardiovascular events (37), a structured evaluation of all of the recognized cardiovascular risk factors and appropriately directed treatment (if needed) are indicated as well.

In view of these facts, primary and secondary prevention also play an important role in the postdischarge care of patients with CAP. Anti-influenza and antipneumococcal vaccination is recommended as standard prevention for all persons over age 60 and as indicated prevention for those with comorbidities. Data on the preventive efficacy of vaccination against influenza in patients with CAP are sparse, but the recommendation to vaccinate is nonetheless justified because of its demonstrated efficacy against influenza and the significance of influenza for the incidence and severity of CAP. With regard to antipneumococcal vaccination, there are data from a large-scale, high-quality, prospective randomized trial showing that a 13 -valent conjugated vaccine (PCV13) lessens the frequency of pneumococcal pneumonia due to the serotypes covered by the vaccine by $45 \%$, and the frequency of the invasive form infection by $75 \%$ (38). The German Federal Standing Committee on Immunization currently recommends the vaccination of all persons aged 60 or older, and of all persons with chronic comorbidities, with the 23-valent polysaccharide vaccine PSV23; sequential vaccination with PCV13 followed by PSV23 is reserved for immunosuppressed persons and those with hepatic or renal failure. On the other hand, the S3 guideline contains a general recommendation for the 13 -valent conjugate vaccine. This discrepancy arises from differences in the assessment of the efficacy of the PSV23 vaccine and of the significance of childhood vaccination for the serotypes affecting adults that are amenable to prevention by vaccination $(39,40)$. Further important matters include smoking cessation and the

\section{Long-term elevation of mortality}

Patients who have been treated in the hospital for CAP have a statistically significant long-term elevation of mortality compared to matched controls. strict reevaluation of the indications for all drugs that have been identified as risk factors for CAP, including sedatives, antipsychotic drugs, and inhaled steroids (in COPD) (10). Optimal oral hygiene and the evaluation and treatment of possible dysphagia in patients with risk factors for it are further important measures for pneumonia prevention whose importance may be underestimated in routine practice (e14, e15).

\section{Conflict of interest statement}

PD Dr. Kolditz has served as a paid consultant for Astra-Zeneca, Bayer, and Basilea. He has received third-party funding for a research project from Pfizer, reimbursement of travel expenses from Pfizer und Astra-Zeneca, and lecture honoraria from Pfizer, Astra-Zeneca, Bayer and Roche.

Prof. Ewig has served as a paid consultant for Pfizer

Manuscript submitted on 29 January 2017, revised version accepted on 13 April 2017.

Translated from the original German by Ethan Taub, M.D.

\section{REFERENCES}

1. Murray CJ, Lopez AD: Measuring the global burden of disease. N Engl J Med 2013; 369: 448-57.

2. Kolditz M, Tesch F, Mocke L, Hoffken G, Ewig S, Schmitt J: Burden and risk factors of ambulatory or hospitalized CAP: a population based cohort study. Respir Med 2016; 121: 32-8.

3. Breitling LP, Saum KU, Schottker B, Holleczek B, Herth FJ, Brenner $\mathrm{H}$ : Pneumonia in the noninstitutionalized older population. Dtsch Arztebl Int 2016; 113: 607-14

4. Ewig S, Birkner N, Strauss R, et al.: New perspectives on community-acquired pneumonia in 388406 patients. Results from a nationwide mandatory performance measurement programme in healthcare quality. Thorax 2009; 64: 1062-9.

5. Kolditz M, Bauer TT, Konig T, Rohde G, Ewig S: 3-day mortality in hospitalised community-acquired pneumonia: frequency and risk factors. Eur Respir J 2016; 47: 1572-4.

6. Corrales-Medina VF, Musher DM, Wells GA, Chirinos JA, Chen L, Fine MJ: Cardiac complications in patients with communityacquired pneumonia: incidence, timing, risk factors, and association with short-term mortality. Circulation 2012; 125: 773-81.

7. Dremsizov T, Clermont G, Kellum JA, Kalassian KG, Fine MJ, Angus $D C$ : Severe sepsis in community-acquired pneumonia: when does it happen, and do systemic inflammatory response syndrome criteria help predict course? Chest 2006; 129: 968-78.

8. Phua J, Ngerng WJ, Lim TK: The impact of a delay in intensive care unit admission for community-acquired pneumonia. Eur Respir $\mathrm{J}$ 2010; 36: 826-33

9. Mortensen EM, Coley CM, Singer DE, et al.: Causes of death for patients with community-acquired pneumonia: results from the Pneumonia Patient Outcomes Research Team cohort study. Arch Intern Med 2002; 162: 1059-64.

10. Ewig S, Hoffken G, Kern WV, et al.: [Management of adult community-acquired pneumonia and prevention—update 2016]. Pneumologie 2016; 70: 151-200.

11. Ewig S, Welte T, Chastre J, Torres A: Rethinking the concepts of community-acquired and health-care-associated pneumonia. Lancet Infect Dis 2010; 10: 279-87.

12. Van Vugt SF, Broekhuizen BD, Lammens $C$, et al.: Use of serum $C$ reactive protein and procalcitonin concentrations in addition to symptoms and signs to predict pneumonia in patients presenting to primary care with acute cough: diagnostic study. BMJ 2013; 346: f2450.

13. Smith SM, Fahey T, Smucny J, Becker LA: Antibiotics for acute bronchitis. Cochrane Database Syst Rev 2014; 3: CD000245. 
14. Schuetz P, Muller B, Christ-Crain M, et al.: Procalcitonin to initiate or discontinue antibiotics in acute respiratory tract infections. Cochrane Database Syst Rev 2012; 9: CD007498.

15. Pletz MW, Rohde G, Schutte H, Bals R, von BH, Welte T: [Epidemiology and aetiology of community-acquired pneumonia (CAP)]. Dtsch Med Wochenschr 2011; 136: 775-80

16. Dumke R, Schnee C, Pletz MW, et al.: Mycoplasma pneumoniae and chlamydia spp. infection in community-acquired pneumonia, Germany, 2011-2012. Emerg Infect Dis 2015; 21: 426-34

17. Bauer TT, Ewig S, Marre R, Suttorp N, Welte T: CRB-65 predicts death from community-acquired pneumonia. J Intern Med 2006; 260: 93-101.

18. Ewig S, Bauer T, Richter K, et al.: Prediction of in-hospital death from community-acquired pneumonia by varying CRB-age groups. Eur Respir $\mathrm{J}$ 2013; 41: 917-22.

19. Choudhury G, Chalmers JD, Mandal $P$, et al.: Physician judgement is a crucial adjunct to pneumonia severity scores in low-risk patients. Eur Respir J 2011; 38: 643-8.

20. Kolditz M, Ewig S, Schutte H, Suttorp N, Welte T, Rohde G: Assessment of oxygenation and comorbidities improves outcome prediction in patients with community-acquired pneumonia with a low CRB-65 score. J Intern Med 2015; 278: 193-202.

21. Kolditz M, Braeken D, Ewig S, Rohde G: Severity assessment and the immediate and long-term prognosis in community-acquired pneumonia. Semin Respir Crit Care Med 2016; 37: 886-96.

22. Creutz $P$, Kothe $H$, Braun $M$, et al.: Failure of ambulatory treatment in CAP patients leading to subsequent hospitalization and its association to risk factors_-prospective cohort study. J Pulmon Resp Med 2013; 3: 140.

23. Kolditz M, Ewig S, Klapdor B, et al.: Community-acquired pneumonia as medical emergency: predictors of early deterioration. Thorax 2015; 70: 551-8.

24. Ferrer R, Martin-Loeches I, Phillips G, et al.: Empiric antibiotic treatment reduces mortality in severe sepsis and septic shock from the first hour: results from a guideline-based performance improvement program. Crit Care Med 2014; 42: 1749-55.

25. Lim HF, Phua J, Mukhopadhyay A, et al.: IDSA/ATS minor criteria aid preintensive care unit resuscitation in severe community-acquired pneumonia. Eur Respir J 2014; 43: 852-62.

26. Salih W, Schembri S, Chalmers JD: Simplification of the IDSA/ATS criteria for severe CAP using meta-analysis and observational data. Eur Respir J 2014; 43: 842-51.

27. Rhodes A, Evans LE, Alhazzani W, et al.: Surviving sepsis campaign: international guidelines for management of sepsis and septic shock: 2016. Intensive Care Med 2017; 43: 304-377.

28. Frat JP, Thille AW, Mercat A, et al.: High-flow oxygen through nasal cannula in acute hypoxemic respiratory failure. N Engl J Med 2015; 372: 2185-96.

29. Sligl WI, Asadi L, Eurich DT, Tjosvold L, Marrie TJ, Majumdar SR: Macrolides and mortality in critically ill patients with community-acquired pneumonia: a systematic review and meta-analysis. Crit Care Med 2014; 42: 420-32.

30. Garin N, Genne D, Carballo S, et al.: Beta-lactam monotherapy vs betalactam-macrolide combination treatment in moderately severe communityacquired pneumonia: a randomized noninferiority trial. JAMA Intern Med 2014; 174: 1894-901

31. Cremers AJ, Sprong T, Schouten JA, et al.: Effect of antibiotic streamlining on patient outcome in pneumococcal bacteraemia. J Antimicrob Chemother 2014; 69: 2258-64.

32. Uranga A, Espana PP, Bilbao A, et al.: Duration of antibiotic treatment in community-acquired pneumonia: a multicenter randomized clinical trial. JAMA Intern Med 2016; 176: 1257-65.

33. Murray C, Shaw A, Lloyd M, et al.: A multidisciplinary intervention to reduce antibiotic duration in lower respiratory tract infections. J Antimicrob Chemother 2014: 69: 515-8.
34. Oz F, Gul S, Kaya MG, et al.: Does aspirin use prevent acute coronary syndrome in patients with pneumonia: multicenter prospective randomized trial. Coron Artery Dis 2013; 24: 231-7.

35. Blum CA, Nigro N, Briel M, et al.: Adjunct prednisone therapy for patients with community-acquired pneumonia: a multicentre, double-blind, randomised, placebo-controlled trial. Lancet 2015; 385: 1511-8.

36. Cangemi R, Calvieri C, Falcone $\mathrm{M}$, et al.: Relation of cardiac complications in the early phase of community-acquired pneumonia to long-term mortality and cardiovascular events. Am J Cardiol 2015; 116: 647-51.

37. Corrales-Medina VF, Alvarez KN, Weissfeld LA, et al.: Association between hospitalization for pneumonia and subsequent risk of cardiovascular disease. JAMA 2015; 313: 264-74.

38. Bonten MJ, Huijts SM, Bolkenbaas M, et al.: Polysaccharide conjugate vaccine against pneumococcal pneumonia in adults. N Engl J Med 2015; 372: 1114-25.

39. Ewig S, Pletz MW, Salzberger B: Pneumokokken-Impfung (1): Kritik an den STIKO-Empfehlungen. Dtsch Arztebl 2017; 114: A-24-7.

40. Falkenhorst G, Leidel J, Bodgan C: Pneumokokken-Impfung (2): Plädoyer für STIKO-Empfehlungen. Dtsch Arztebl 2017; 114: A-28-30.

\section{Corresponding author}

PD Dr. med. Martin Kolditz

Abteilung für Pneumologie, Medizinische Klinik und Poliklinik

Universitätsklinikum Carl Gustav Carus

Fetscherstr. 74,

01307 Dresden, Germany

martin.kolditz@uniklinikum-dresden.de

Supplementary material

For eReferences please refer to:

www.aerzteblatt-international.de/ref4917

Case illustration:

www.aerzteblatt-international.de/17m0838
FURTHER INFORMATION ON CME

This article has been certified by the North Rhine Academy for Postgraduate and Continuing Medical Education. Deutsches Ärzteblatt provides certified continuing medical education (CME) in accordance with the requirements of the Medical Associations of the German federal states (Länder). CME points of the Medical Associations can be acquired only through the Internet, not by mail or fax, by the use of the German version of the CME questionnaire. See the following website: cme.aerzteblatt.de. Participants in the CME program can manage their CME points with their 15-digit "uniform CME number" (einheitliche Fortbildungsnummer, EFN). The EFN must be entered in the appropriate field in the cme.aerzteblatt.de website under "meine Daten" ("my data"), or upon registration. The EFN appears on each participant's CME certificate. This CME unit can be accessed until 4 March 2018, and earlier CME units until the dates indicated:

- "Impingement Syndrome of the Shoulder" (Issue 45/17) until 4 February 2018,

- "Fitness to Drive in Cardiovascular Disease" (Issue 41/17) until 7 January 2018 


\section{Please answer the following questions to participate in our certified Continuing Medical Education program. Only one answer is possible per question. Please select the most appropriate answer.}

\section{Question 1}

When a patient is admitted to the hospital via the emergency room for community-acquired pneumonia, what should be done first?
a) isolation of the patient on the hospital ward
b) individualized fluid management
c) initiation of noninvasive ventilation
d) identification of high-risk patients
e) administration of normal saline

\section{Question 2}

Which of the following is a component of risk assessment in outpatients with suspected CAP, according to the CRB-65 criteria?
a) laboratory tests
b) reddish skin discoloration on the chest
c) respiratory frequency
d) clinical course over the ensuing 24 hours
e) risk factors in the patient's home situation

\section{Question 3}

How is CAP generally distinguished from acute bronchitis that does not require treatment with antibiotics?
a) by a focal auscultatory abnormality
b) by the elevated body temperature
c) by spirometry
d) by the demonstration of an infiltrate
e) by measurement of the C-reactive protein

\section{Question 4}

Which of the following findings in a hospitalized patient with community-acquired pneumonia is an indication for intensified monitoring?
a) respiratory rate $12-18 / \mathrm{min}$
b) oxygen saturation $>95 \%$
c) $\mathrm{pH} 7.36-7.44$
d) leukocyte count $<6000$ cells $/ \mu \mathrm{L}$
e) platelet count $<100000 \mathrm{cells} / \mu \mathrm{L}$

\section{Question 5}

A 42-year-old man is given the diagnosis of CAP in the emergency room. He wants to be treated as an outpatient. His temperature is $38.2^{\circ} \mathrm{C}$, his blood pressure is $130 / 80 \mathrm{mmHg}$, his respiratory rate is $24 / \mathrm{min}$, and his oxygen saturation is $96 \%$. What is the appropriate decision?

a) Risk stratification implies that outpatient treatment is possible.

b) He should not be treated as an outpatient because of the elevated risk of an impairment of consciousness.

c) He should not be treated as an outpatient because he is febrile.

d) Outpatient treatment is not yet possible because of the risk of respiratory insufficiency.

e) The serum procalcitonin concentration must be measured before any decision is taken.

\section{Question 6}

What positive effect was obtained in an interventional trial by the use of the so-called minor criteria in patients with severe CAP?

a) The patients were discharged from the hospital an average of 2 days earlier.

b) On long-term follow-up, $92 \%$ of the patients were still complying with the recommended preventive measures against CAP.

c) Antibiotic consumption was markedly reduced.

d) Mortality was lowered from $24 \%$ to $6 \%$.

e) Timely measurement of the lactate concentration resulted in a reduction of the number of patients who had to be transferred to the intensive care unit.

\section{Question 7}

For which patients with CAP is a macrolide drug recommended as initial antibiotic treatment, in addition to a beta-lactam?
a) patients aged 65 and older
b) patients with acute organ dysfunction
c) patients undergoing ambulatory treatment
d) patients with accompanying COPD
e) patients with a markedly elevated CRP concentration

\section{Question 8}

When might the administration of acetylsalicylic acid to a patient with community-acquired pneumonia be indicated?
a) If clinical stability has not been achieved after 3-5 days of appropriate treatment.
b) If influenza virus is demonstrated to be present.
c) If the patient does not tolerate the additional administration of a macrolide.
d) If a hospitalized patient develops cardiovascular complications.
e) If the systolic blood pressure is below $90 \mathrm{mmHg}$.

\section{Question 9}

What drug should be given as initial therapy for severe CAP, and in what dose?
a) amoxicillin $250 \mathrm{mg} \mathrm{q} 12 \mathrm{~h}$
b) cefuroxime $0,5 \mathrm{~g} \mathrm{q12h}$
c) penicillin $400 \mathrm{mg}$ qd
d) piperacillin/tazobactam $4.5 \mathrm{~g} \mathrm{q6}-8 \mathrm{~h}$
e) ciprofloxacin $500 \mathrm{mg} \mathrm{q12h}$

\section{Question 10}

How high is the in-hospital mortality of patients with CAP who are treated as inpatients?
a) ca. $33 \%$
b) ca. $25 \%$
c) ca. $19 \%$ in women and $22 \%$ in men
d) less than $1 \%$
e) ca. $13 \%$ 


\section{Supplementary material to:}

\section{Community-Acquired Pneumonia in Adults}

\section{Martin Kolditz and Santiago Ewig}

Dtsch Arztebl Int 2017; 114: 838-48. D0I: 10.3238/arztebl.2017.0838

\section{eREFERENCES}

e1. Van Vugt SF, Verheij TJ, de Jong PA, et al.: Diagnosing pneumonia in patients with acute cough: clinical judgment compared to chest radiography. Eur Respir J 2013; 42: 1076-82.

e2. Pakhale S, Mulpuru S, Verheij TJ, Kochen MM, Rohde GG, Bjerre LM: Antibiotics for community-acquired pneumonia in adult outpatients. Cochrane Database Syst Rev 2014; CD002109.

e3. Hortmann M, Heppner HJ, Popp S, Lad T, Christ M: Reduction of mortality in community-acquired pneumonia after implementing standardized care bundles in the emergency department. Eur $\mathrm{J}$ Emerg Med 2014; 21: 429-35.

e4. Gwak MH, Jo S, Jeong T, et al.: Initial serum lactate level is associated with inpatient mortality in patients with communityacquired pneumonia. Am J Emerg Med 2015; 33: 685-90.

e5. Von Baum H, Welte T, Marre R, Suttorp N, Lück C, Ewig S: Mycoplasma pneumoniae pneumonia revisited within the German Competence Network for Community-acquired pneumonia (CAPNETZ). BMC Infect Dis 2009; 9: 62.

e6. Wellinghausen N, Straube E, Freidank H, von Baum H, Marre R, Essig A: Low prevalence of chlamydia pneumoniae in adults with community-acquired pneumonia. Int J Med Microbiol 2006; 296: 485-91.

e7. Postma DF, van Werkhoven $\mathrm{CH}$, van Elden LJ, et al.: Antibiotic treatment strategies for community-acquired pneumonia in adults. N Engl J Med 2015; 372: 1312-23.

e8. Von Baum H, Welte T, Marre R, Suttorp N, Ewig S: Communityacquired pneumonia through enterobacteriaceae and pseudomonas aeruginosa: diagnosis, incidence and predictors. Eur Respir J 2010; 35: 598-605.

e9. Lehnert R, Pletz M, Reuss A, Schaberg T: Antiviral medications in seasonal and pandemic influenza - a systematic review. Dtsch Arztebl Int 2016; 113: 799-807.

e10. Aliberti S, Ramirez J, Cosentini R, et al.: Acute myocardial infarction versus other cardiovascular events in community-acquired pneumonia. ERJ open research 2015; 1.

e11. Falcone M, Russo A, Cangemi R, et al.: Lower mortality rate in elderly patients with community-onset pneumonia on treatment with aspirin. J Am Heart Assoc 2015; 4: e001595.

e12. Torres A, Sibila 0, Ferrer M, et al.: Effect of corticosteroids on treatment failure among hospitalized patients with severe community-acquired pneumonia and high inflammatory response: a randomized clinical trial. JAMA 2015; 313: 677-86.

e13. Eurich DT, Marrie TJ, Minhas-Sandhu JK, Majumdar SR: Ten-year mortality after community-acquired pneumonia. A prospective cohort. Am J Respir Crit Care Med 2015; 192: 597-604.

e14. Bassim CW, Gibson G, Ward T, Paphides BM, Denucci DJ: Modification of the risk of mortality from pneumonia with oral hygiene care. J Am Geriatr Soc 2008; 56: 1601-7.

e15. Almirall J, Rofes L, Serra-Prat M, et al.: Oropharyngeal dysphagia is a risk factor for community-acquired pneumonia in the elderly. Eur Respir J 2013; 41: 923-8. 


\section{Case illustration: community-acquired pneumonia}

A 56-year-old man presented to the emergency room with acute malaise, fever to $38.4^{\circ} \mathrm{C}$, dyspnea, and a productive cough with yellowish sputum. He had no other serious medical conditions and was taking no medications. He stated that he had smoked approximately 15 cigarettes a day for the past 20 years.

On examination, his general condition was somewhat impaired, but he was fully alert and oriented. His respiratory rate was $26 / \mathrm{min}$, his blood pressure was $120 / 55 \mathrm{mmHg}$, and his heart rate was $100 / \mathrm{min}$ (slight tachycardia). Inspiratory rales were heard over the inferior and middle lung fields on the right. The physical examination was otherwise unremarkable.

A chest $\mathrm{x}$-ray showed marked consolidation in the right upper and middle lobes and linear paracardiac opacities in the left lower lobe (Figure). Capillary blood-gas analysis showed an arterial partial oxygen pressure $\left(\mathrm{paO}_{2}\right)$ of $78 \mathrm{mmHg}$ and an arterial partial carbon dioxide pressure $\left(\mathrm{PaCO}_{2}\right)$ of $32 \mathrm{mmHg}$ on room air.

These findings established the diagnosis of bilateral community-acquired pneumonia. Risk stratification yielded a CRB-65 score of 1 (diastolic hypotension), implying an elevated risk of death.

The patient was admitted to the hospital. Intensified monitoring was indicated as recommended in the 2016 S3 guideline; documentation of the respiratory rate and hemodynamic status every three hours was ordered. Two sets of blood cultures were taken, and urine antigen tests were performed for pneumococci and for Legionella pneumophila serogroup 1. Sputum could not be obtained for analysis. The antigen test for pneumococci was positive. The blood cultures were negative. These findings established the diagnosis of pneumococcal pneumonia.

The CRP concentration was $15.1 \mathrm{mg} / \mathrm{dL}$, and the serum potassium level was mildly low at 3.5 $\mathrm{mmol} / \mathrm{L}$. All other laboratory findings were unremarkable; in particular, there was no leukocytosis and no renal dysfunction.

The patient was treated with ampicillin/sulbactam $3 \mathrm{~g}$ IV q8h and clarithromycin $500 \mathrm{mg}$ po bid, as well as with normal saline IV at $40 \mathrm{ml} / \mathrm{hr}$.

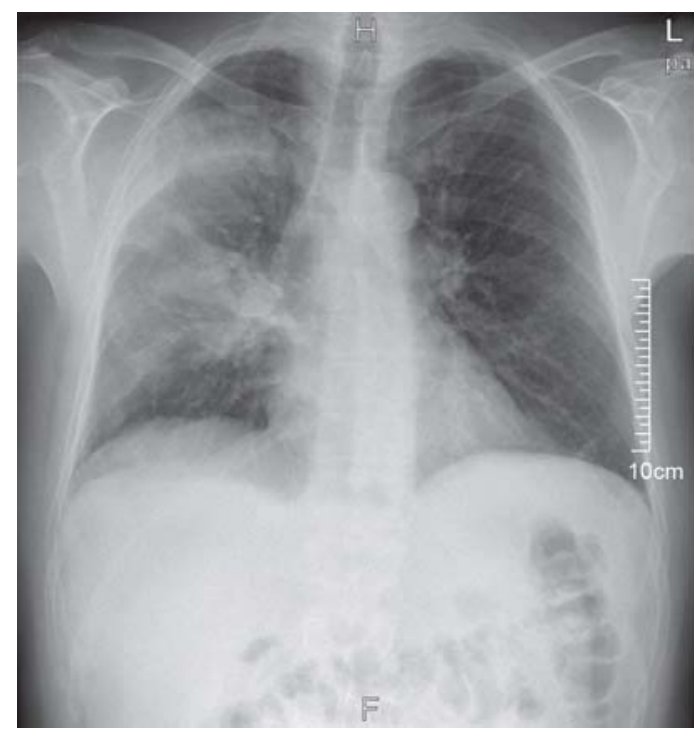

Chest X-ray: marked consolidation in the right upper and middle lobes, linear paracardiac opacities in the left lower lobe.

The patient's blood pressure became stable within three hours. His condition improved rapidly and permanently; after the first 24 hours, he was no longer febrile. The CRP concentration fell to $8.0 \mathrm{mg} / \mathrm{dL}$ and the potasssium concentration returned to normal.

At this point, intravenous ampicillin/sulbactam and oral clarithromycin were stopped and amoxicillin $1 \mathrm{~g}$ po tid was given.

The patient was discharged home after 5 days in the hospital with instructions to keep taking amoxicillin for two more days (7 days of antibiotics total). An outpatient follow-up chest x-ray four weeks after admission showed only mild residual opacities.

\section{Comment}

This is the typical course of moderately severe community-acquired pneumococcal pneumonia. Hypotonia and multilobar infiltrates implied an elevated risk of death, but early and appropriate antibiotic treatment led to prompt improvement. Intensified monitoring was indicated so that impending sepsis could be recognized and treated without delay. 